\title{
Improving Energy Efficiency and Environmental Sustainability of Commercial Insulation
}

\author{
Celine Manoosingh ${ }^{1}$, James Mihelcic ${ }^{2} \&$ Manjriker Gunaratne ${ }^{2}$ \\ ${ }^{1}$ Georgia Southern University \\ ${ }^{2}$ University of South Florida \\ Correspondence: Celine Manoosingh, Georgia Southern University. E-mail: cmanoosingh@gmail.com \\ Received: June 24, 2014 \\ Accepted: July 10, 2014 \\ Online Published: April 12, 2015 \\ doi:10.5539/eer.v5n1p63 \\ URL: http://dx.doi.org/10.5539/eer.v5n1p63
}

\begin{abstract}
With increasingly stringent energy standards set in place by the Department of Energy, energy efficiency is becoming a paramount concern to manufacturers of appliances. Additionally, the production and disposal of the voluminous amount of polyurethane foam commonly utilized as insulation in refrigeration units poses a significant environmental challenge. In this context, this study investigated an alternative insulation for use in commercial refrigerator/freezer units. A prototype exploring the use of evacuated packets of pyrogenic silica substituting for conventional insulation was assessed. Assessment criteria included experimental comparison of heat transfer characteristics and the energy efficiency of the new insulation as well as its life cycle as it is related to environmental sustainability. Results indicate that in the new insulation design applied to the unit's cover, heat flux decreased by an average of 36\%, and energy efficiency improved by $5.1 \%$ over a 24 hour period. The new insulation design also resulted in improved environmental sustainability, resulting in a savings of 0.257 metric tons of $\mathrm{CO}_{2} \mathrm{e}$ over 20 years for a single unit. Results provide an alternative insulation design for use in commercial refrigerator and freezers, and a framework by which to assess the efficiency and environmental performance of similar products.
\end{abstract}

Keywords: life cycle assessment, insulation, refrigerator, greenhouse gas emissions, carbon dioxide, built environment, LEED

\section{Introduction}

In the United States, resident and commercial buildings together use more energy and emit more carbon dioxide than either the industrial or transportation sector. In fact, infrastructure in the United States now accounts for $41 \%$ of all energy needs, two thirds of electricity consumption, and one eighth of all water use (U.S EIA, 2011). Commercial refrigeration systems also account for approximately $8 \%$ of all commercial building energy use (DoE, 2011).

Since the introduction of mandated energy efficiency standards (e.g., in the United States, Energy Star) the goal of every refrigerator commercial and residential manufacturer has been to improve the design and processing of the refrigerator unit to improve efficiency and sustainability. This is especially important because the average refrigerator is comprised of over twelve different types of material, including voluminous amounts of polyurethane foam (AHRI, 2011). Energy improvements in the United States are typically measured in power savings, as expressed by KWh/day. The Environmental Protection Agency (EPA) also requires that the end-of-life of a unit include safe disposal and with minimal environmental impact. Unfortunately, the volume of insulation material, as well as variances in material composition make efficient reuse and recycling difficult. In fact, the process of completely recycling a commercial refrigerator is in fact both tedious and inefficient. In particular, the disposal of polyurethane foam used for insulation presents a significant environmental challenge. Polyurethane foam serves a dual purpose in commercial refrigerators. In addition to functioning as the primary insulator of the unit, foam is injected throughout the body of the unit to provide structural support. It has been traditionally used as the insulator of choice due to its relatively high ' $R$ ' value, or the ability of a material to resist heat. When polyurethane foam is incinerated, it emits carbon monoxide, nitrogen oxides, isocyanine, acrylonitrile, and hydrogen cyanide in levels exceeding those allowed by the EPA (EPA, 2011).

Significant strides have been made in improving the energy efficiency of residential refrigeration, but few are 
reported in the field of commercial refrigeration. While no literature was identified for this study on efforts to improve energy efficiency in non-residential refrigeration units, a substantive review of advances in alternative technology to improve the energy efficiency of residential unit is provided by Bansal et al. (2011). That study reviewed emerging technologies that have the potential to improve energy metrics in residential refrigerators. The review concluded that significant breakthroughs are needed for alternative mechanical systems to compete with traditional vapor compression technology. A key similarity in many publications evaluating energy efficiency improvements in refrigerators (e.g., Waide, 2002; Boardman 2004; Mahlia, 2010) is that a fundamental change is needed in the industry. In fact, many of the options explored by major residential refrigerator manufacturers involve the reduction of the amount of polyurethane foam used in the insulation.

$\mathrm{Wu}$ et al. (1998) investigated the heat transfer characteristics of polyurethane foam and showed that evacuating the air from the foam cells can reduce the thermal conductivity of the polyurethane foam in a refrigerator by up to $75 \%$. While the idea of alternative types of insulation have been explored by many manufacturers producing residential refrigeration units, advanced insulation technologies to reduce the amount of heat gained by the refrigerator storage cabinet is limited by manufacturers' desire to achieve maximum internal volume for product storage. Additional limitations are cost of the insulation material, available manufacturing techniques and labor, and material degradation over time (DoE, 2010).

Vacuum paneling consists of a rigid core with cells of evacuated air and is a developing technology to increase energy efficiency. This type of insulation in buildings and other devices has gradually increased in recent years, as manufacturers have developed more economic panels. A redesigned vacuum panel reduces the volume of air molecules in an evacuated space, thus reducing the rate of heat transfer. There are two main approaches to vacuum technology: vacuum powder and vacuum paneling. Vacuum paneling can consist of powder- and fiber-filled panels, compact vacuum insulation (with stainless steel walls), or aerogels. Other insulation techniques explored in previous research are the use of baffle-type argo-filled panels, proven to substantially decrease thermal conductivity (Kudoh, 2006). When vacuum paneling was employed in residential refrigeration units, a $20.4 \%$ energy savings was achieved (EPA, 2009). Vacuum paneling prototypes were also tested by Eberhardt (2007) and Weaver et al. (1996) and they observed respective improvements in energy efficiency of 15\% to $25 \%$. An advanced version of polyurethane foam was also developed by Parenti (2007) that improved the efficiency of the foam insulation. It combines the idea of the vacuum panel with traditional injection molding. The insulation method employed in that study was found to increase energy efficiency by $35 \%$.

Bouquerel, Duforestel, Baillis and Rusaouen, (2012) investigated heat transfer through a VIP in a building through empirical models. While the applications are very different in comparison to refrigerators, the heat transfer can be determined through similar models. There has been some debate as to the effectiveness of the filling materials used in VIPs. Kwon, Jang, Jung and Song (2009) examined the use of powder, foam, and fibers as filling materials for VIPSs. The results show that that the solid conductivities of the fiber and more solid types of filling for the VIP insulation are lower than those of the powder and foam due to the relatively long thermal path. It can concluded from examination of the literature that the higher density of the filling material of the VIP, the more effective the insulation is for the case of commercial refrigeration. While vacuum insulation panels are considered one of the foremost technologies for insulation in buildings, the technology is less than ideal for use in refrigerators due to the cost as well as the ability of vacuum insulation panels to be cut to fit specialized models. Another emerging technology in the insulation field is industrial grade silica beads and aerogels. Silica is well known for its thermal resistance. In a study by Fricke, Hummer and Scheuerpflug (1995), vitreous silica was compared to aerogels. The result showed an increase in radiative transfer through aerogels, but a significant decrease in thermal conduction with the use of aerogels. Vitreous silica was also proven to be an excellent inhibitor to heat transfer. While aerogels are not as yet feasible for use in commercial refrigeration systems due to its high cost, silica in the form of non-porous beads and fibers are still a viable option to consider.

Further, a study by Zhao (2006) investigated the radiative heat transfer properties of a silica aerogel composite. The results show that the effectiveness of this type of material is greatly increased when the inclination, diameter and length are configured based on experimental results. The optimum parameters combined with the fibrous silica utilized in the study produce an effective insulation. The idea of combining silica as the filling material for a vacuum panel was explored by Fricke et al. (1995). The authors assert that even though VIPs have a thermal resistance ten times that of foam-based insulation of the same thickness, the filling material should contribute to the heat- bearing load, and will then reduce some of the associated draw-backs related to VIPs-i.e.- the loss of vacuum over time. The study suggests fumed silica as a filling material, where the suggested silica material has a thermal conductivity of about $0.004 \mathrm{~W} \mathrm{~m}^{-1} \mathrm{~K}^{-1}$ at room temperature. Another material consideration was employed by Yu, Li and Zhu (2009) where thermal performance of insulation was investigated through the walls 
of a low temperature cold box. The results of their testing indicate that a reflective heat shield significantly reduced heat losses by up to $18 \%$. The study also showed a reduction in heat loss when aluminum foil was used as an alternative to the heat shield.

Accordingly, based on the literature review and the need to improve energy efficiency and environmental sustainability of refrigeration, the primary objective of this study is to explore commercial refrigeration design measures that will reduce the volume of polyurethane foam utilized in commercial-grade refrigeration units, while improving or sustaining key metrics such as the maximum allowable energy consumption, internal volume, and integrated average temperature. This is achieved through the development and laboratory testing of an alternative insulation prototype, evaluated by measurements of energy consumption and heat flux in a redesigned commercial refrigerator/freezer unit. The research also evaluates the redesigned insulation in terms of its environmental sustainability through the use of life cycle assessment. With increasingly stringent and mandatory efficiency regulations being employed by Energy Star, the California Energy Commission, and the United States Department of Energy, the need for redesign of key refrigerator components is vital. In fact, research shows that if all commercial and residential solid door refrigerators and freezers were just replaced with Energy Star models, greenhouse gas emissions would be reduced by 6 billion pounds (Energy Star, 2011). Hence, the market success of refrigerator manufacturers relies on innovative and efficient unit design.

\section{Methods}

\subsection{Power Consumption and Heat Flux Testing}

A commercial $5 \mathrm{ft}^{3}{ }^{3}$ Whirlpool refrigerator chest (Model EH070FXRQ), shown in Figure 1 (left), was outfitted with measurement equipment for testing and evaluation purposes. Heat flux sensors, Omega- HSF-4 (Stamford, Connecticut) and thermocouples, Omega- Type-T (Stamford, Connecticut) were installed in the internal refrigerator/freezer cabinet, in locations described in the right of Figure 1, to measure heat transfer and to monitor internal temperature respectively. Sensors 1 and 2 were placed in the cover of each unit, where the insulation design was varied depending on the unit; while sensors 3 and 4 were placed across the polyurethane insulation of the walls, that remained unchanged, to act as the control. A power meter, P3 Kill-A-Watt (New York, New York) was utilized to determine the total energy used by the unit over the testing period.

The refrigerator/freezer was placed, unmodified, in a testing chamber to a controlled ambient temperature of $75^{\circ} \mathrm{F}$, relative humidity of $45 \%$ and air pressure of $101 \mathrm{MPa}$, as prescribed by the ASHRAE $72-2005$ testing standard (ASHRAE, 2005). This unchanged, traditionally insulated unit is referred in this study as 'Unit A'. Heat flux and power consumption were measured and recorded over a 24 hour period for Unit A. Details of the test are provided later in this manuscript.

After the testing of Unit A was complete, the cover of the refrigerator/freezer chest was removed; the polyurethane insulation located in the cover was removed and replaced with an alternative insulation configuration consisting of an insulation cartridge in which packets of evacuated silica are inserted into a honey-comb like recycled plastic structure. A reflective heat shield made of recycled polyester fiber encapsulated the cartridge, and a small amount of polyurethane was applied to seal the structure. This unit is referred to as 'Unit B'. Unit B was then placed in the testing chamber and was made to undergo the same heat flux and power consumption testing over a 24 hour period as Unit A.

In both the traditional unit (Unit A) and the modified unit (Unit B), the mechanism by which cooling occurs remained the same. A vapor-compression system was utilized, wherein the refrigerant travels along tubing through the compressor. From there, the refrigerant moves through smaller tubes to the evaporator. The movement of Freon from the compressor to the evaporator causes a significant drop in the pressure of the liquid, allowing it to absorb warm air from the internal compartment, changing from liquid to heated gas which then moves through the coils of the condenser and is released into the cooler ambient air. The cycle then refreshes itself when Freon loses heat and returns to a liquid state. 

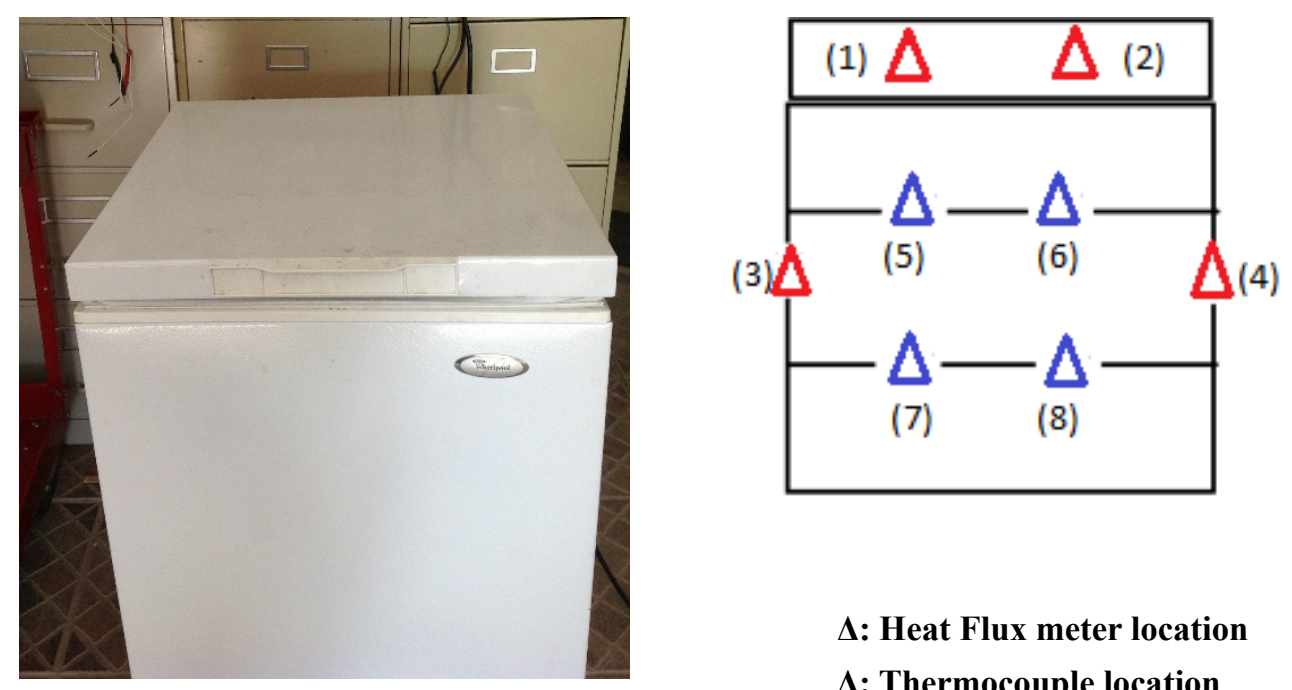

\section{$\Delta$ : Heat Flux meter location}

\section{$\Delta$ : Thermocouple location}

Figure 1. The testing unit was a $5 \mathrm{ft} .{ }^{3}$ commercial refrigerator/freezer (left) outfitted with a network of monitors (right) used to measure heat flux through insulation and internal temperature of the unit.

Polyurethane insulation was also used in the cover and walls of the traditional commercial refrigerator/freezer. Figure 2 illustrates the various materials that typically comprise the cover and walls of these units. In the system studied here, two separate metal trays measuring 20.7 in. $\times 23.8$ in were coated with polystyrene to form the exterior of the unit. The process by which it was manufactured involved molding steel sheeting to form the inner and outer surfaces of the walls and chest cover. The inner plastic sheeting was molded separately and attached to the metal tray by plastic fasteners. Polyurethane was injected into the 3.35 in. cavity between the outer steel and inner plastic liner. The injected polyurethane took the form of foam and is inserted at a pressure of $4.5 \mathrm{lbs} / \mathrm{in}^{2}$. After a 36 hour setting time, this foam hardened between the liners and the steel strips and provided insulation and structural support to the unit.

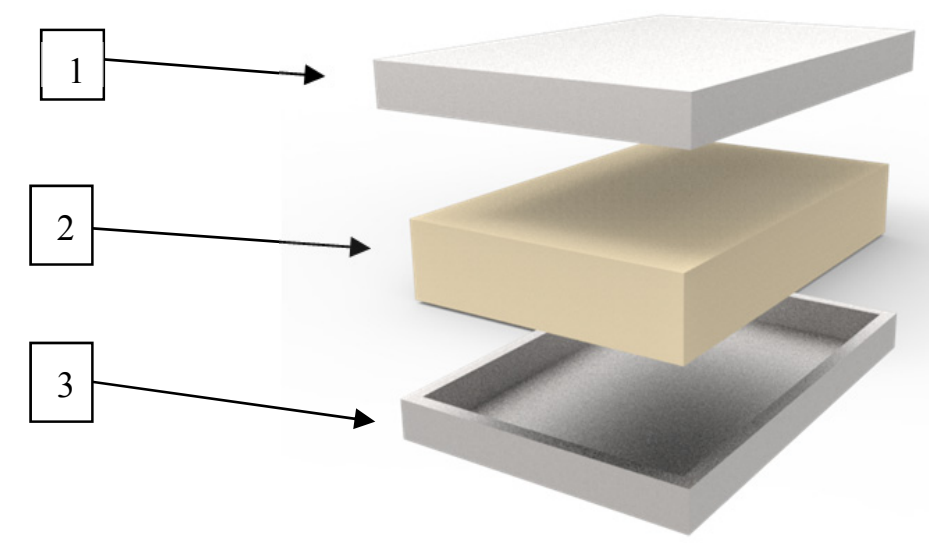

Figure 2. Traditional refrigerator cover and walls incorporates insulation that is comprised of liquid polyurethane foam that is injected in between two metal trays and allowed to harden. (1) external metal tray with an acrylic coating; (2) hardened polyurethane, the primary insulator; (3) opposite metal tray also coated with acrylic.

Figure 3 illustrates the idealized alternative insulation design, employed in the cover of Unit B. A specific assembly sequence to optimize energy efficiency as well as material recovery at the end of life was developed. The redesigned insulation utilized two separate production sequences before the final assembly of the refrigerator/freezer chest. The first part of the production sequence was the fabrication of the insulation cartridge. The insulation system employed a honey-comb cartridge; manufactured using vacuum formed recycled plastic obtained from the waste stream of the disassembly and recovery facility to form hexagonal cavities of size 5" 
with an outside 90 degree flange, 1 " wide with predrilled holes. The recycled plastic 'honeycomb' mold was used for its ability to provide structural support to the unit.

Cavities within the honeycomb sheet were subsequently sprayed with heat release adhesive and fitted with 3 in. ${ }^{2}$ hexagonal plastic packets of industrial grade fumed silica beads. Specialized industrial grade fumed silica was utilized due to its ability to absorb moisture, prevent conductive and convective heat losses, and regenerate after use. In the production of the silica packets, each plastic packet was subjected to the generation of a vacuum to a level of $3.4 \mathrm{kPa}$. The generation of a vacuum ensured that heat loss from the cold cabinet to the inside air was minimized. The honeycomb cartridge was manufactured with proportionate dimensions so that could be inserted into the external and internal refrigerator metal trays, the metal skin was also manufactured with an inside flange with predrilled holes proportionate to the cartridge.

The second part of the production sequence began with outfitting the metal skin of both the refrigerator/freezer walls and chest. Heat release adhesive was sprayed into space between the metal tray and a reflective heat shield was inserted into the tray for further insulation. The insulation cartridge manufactured in part 1 of the production sequence was fitted into the space between the metal tray and a small amount of polyurethane foam was injected into the area between the cartridge and the external metal. The cartridge was sealed into the metal tray with plastic panel retainer clips. The walls and the cover of the refrigerator/freezer were assembled through traditional means: e.g., welding at the points of contact. After the assembly was fully complete, the white plastic acrylic was fastened to the outside of the unit to maintain traditional aesthetics.

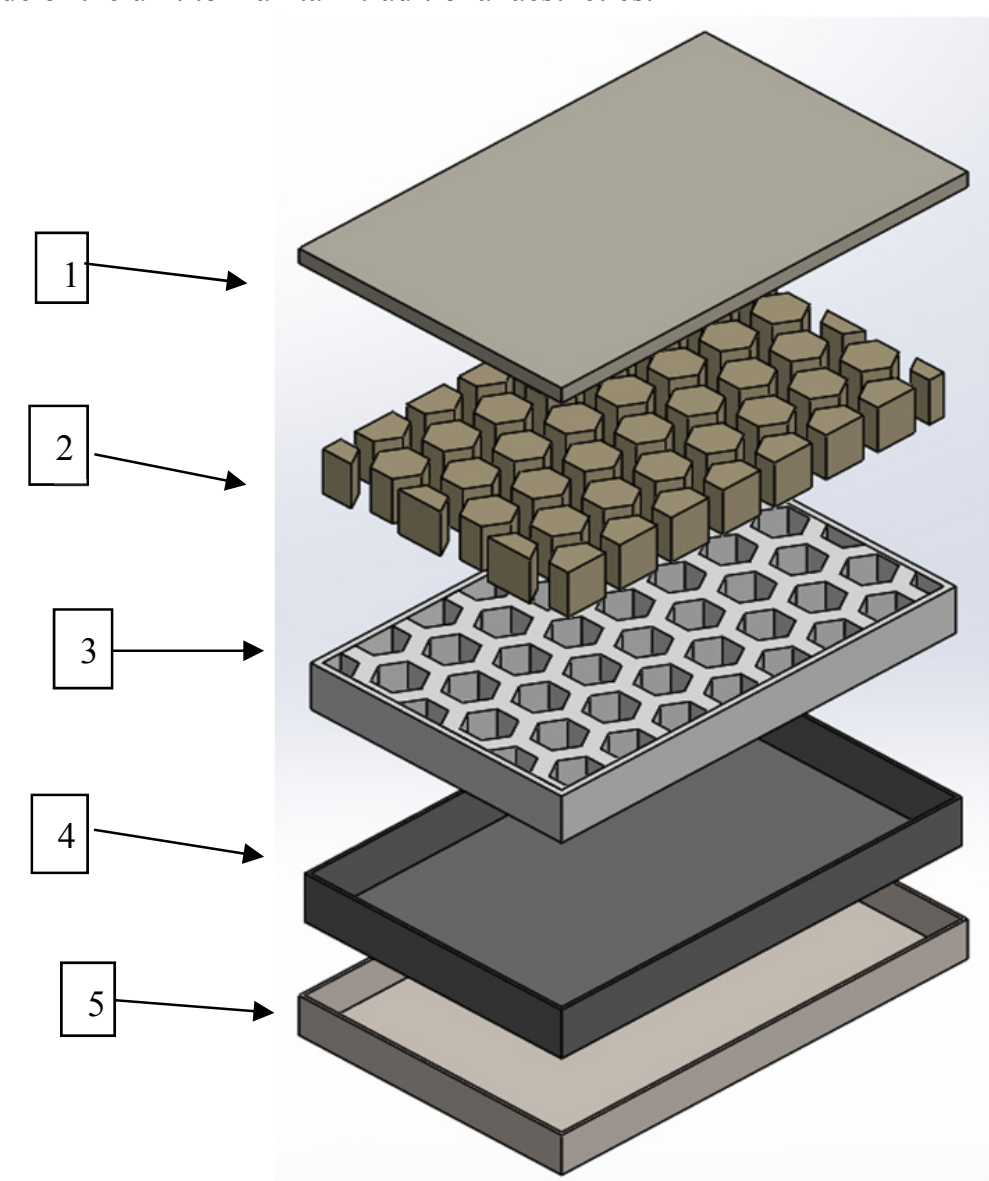

Figure 3. Commercial freezer chest cover. (1) external metal cover that is covered with a white acrylic sheet; (2) packets of evacuated fume silica are inserted into the recycled plastic cartridge (3); (4) reflective heat shield that encompasses the cartridge; (5) external metal tray that is also covered with a sheet of white acrylic for standard aesthetic purposes.

The refrigerator/freezer unit utilized in the testing measured 20.7 in. $\times 23.8 \mathrm{in.} \times 34.45$ in., had a net weight of $117 \mathrm{lbs}$., and was outfitted with an $115 \mathrm{~V} \mathrm{AC}$ reciprocating hermetically-sealed compressor, automatic electrical defrost heater, and was charged with 140 grams of R134a refrigerant as a working fluid. The compressor was a single fixed-speed type, with thermostat based on and off control. The testing chamber contained the refrigerator 
unit, laptop computer, and other test equipment. The control room was outfitted with a thermostat, humidity gage, and room pressure monitor. The humidity, air pressure, and temperature in the room were brought to steady state conditions as prescribed by the ASHRAE standard 72-2005 which mandated a humidity level of $45 \%$, air pressure of $101 \mathrm{MPa}$, and a constant ambient temperature of $75^{\circ} \mathrm{F}$.

Power consumption of each unit was also measured simultaneously. The temperature and heat flux measurements obtained from the measurements were recorded digitally at the top of every hour of the test. The testing began after 7 hours after the unit temperature had been stabilized under steady state conditions. The heat flux data across sensors 1 and 2 (labeled in Figure 1) were collected beginning at hour (7).

\subsection{Methodology for Life Cycle Assessment}

This component of the research examines the life cycle consequences associated with the two different types of insulation utilized in commercial refrigeration study. This study utilized SimaPro life-cycle inventory (LCI) software (Amsterdam, The Netherlands). SimaPro integrates ISO 14040: 2006 standards (International Organization for Standardization, 2006) for environmental management and standardized LCI formats to analyze model data. This version has built-in databases from various sources containing energy and emission data characteristics of those found in the United States and abroad. In addition to manufacturer data discussed in the previous section, these databases were utilized to quantify emissions from unit processes.

The manufacturing of a commercial refrigerator/freezer typically takes place in one central facility where a number of mechanical components, manufactured separately are assembled. The compressor, evaporator and condenser are usually manufactured by a subsidiary of the main company or a separate entity, and then assembled in the final unit. The insulation for the unit, as well as the metal trays coated with acrylic, are typically added at the main manufacturing and assembling facility before the final assembly takes place. The functional unit for this life cycle assessment was a generation of an internal temperature of $-6^{\circ} \mathrm{F}$ for 200,000 hours of operation, under average ambient conditions of $75^{\circ} \mathrm{F}$ and $40 \%$ humidity. This is equivalent to roughly 20 years of operation, the typical life span of commercial refrigerator/freezer unit of this type.

The system boundary of the life cycle component of the research is shown in Figure 4. It includes the inputs from raw material acquisition, material processing, manufacturing, use, decommissioning, treatment and disposal and recycling, where material is salvaged from the decommissioning and recycling of the original unit for one cycle of remanufacturing.

In order to create a realistic life cycle assessment, the following assumpions about the manufacture, use and disposal scenarios for the two types of units are made:

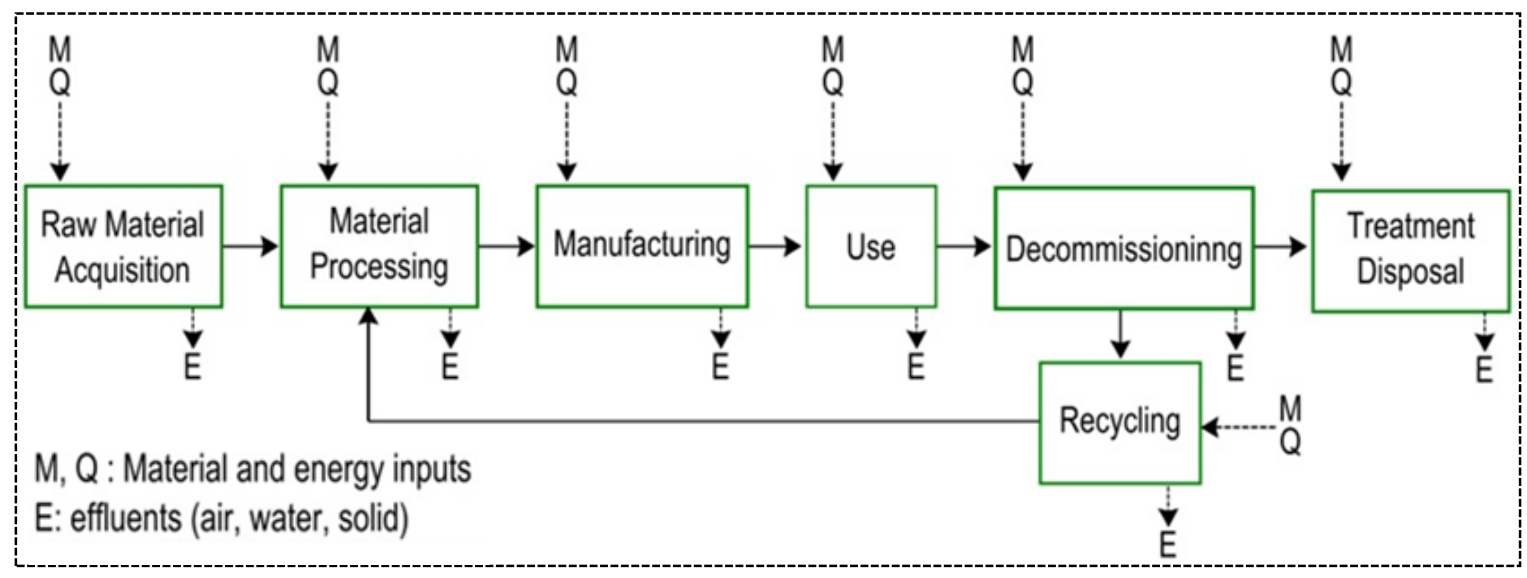

Figure 4. LCA system boundary of this research. The LCA encompasses material and energy inputs from raw material acquisition, material processing, manufacturing, use, decommissioning, recycling, treatment and disposal, and one cycle of remanufacturing.

Between January and July 2012, the primary data for the reporting year 2011 were collected from three representative manufacturers contacted for the study. The manufacturers were surveyed using a self-administered questionnaire based on study objectives, and in accordance with ISO protocol. The participating companies were ensured confidentiality, and all three participated in the study. The returned surveys indicated a combined production of 3.64 million $5 \mathrm{ft}^{3}$ units was manufactured in 2011 by these factories combined, accounting for $58 \%$ 
of the total production of these types of units internationally. Incomplete data sets were completed by conducting follow up telephone calls and interviews with representatives from each manufacturing plant.

Product yields reported in the survey showed how the input materials were manufactured into products, co-products and waste. It was observed by manufacturers that approximately $65 \%$ of the input materials were directly utilized in unit production. The other $35 \%$ was scrapped and quite frequently ended up being disposed of in a landfill. The manufacturer surveys also indicated that all deliveries of raw materials to the manufacturer facility were by truck. It was found by this research that manufacturers typically selected raw material suppliers based on geographic proximity to decrease costs associated with transportation. Environmental burdens associated with this transportation are included in the cumulative system boundary assessment. Energy and material utilized as packaging material are not included within the bounds of this study.

It should be noted that each factory outsourced the manufacturing of some components of the refrigerator/freezer, but were asked to include this data in the data reporting. For the purposes of this study, independent companies that supply components or whole parts to the parent factories were included in the data reported by those respective parent companies. The factories were also asked to document what data were unavailable with regard to reporting this type of information; incomplete data was assumed based on existing relevant sources from built-in inventory in SimaPro. The data sets available in SimaPro were chosen based on their geographic relevance to this study. The complete list of sources utilized is listed in Table 1 . The manufacturer surveys proved to be quite useful in determining the manufacturing techniques and processes.

Table 1. LCA unit processes and corresponding data sources

\begin{tabular}{|c|c|}
\hline LCA Unit Process & Data Source \\
\hline \multicolumn{2}{|l|}{ Fuel, Energy and Raw Material Extraction } \\
\hline Input materials & Manufacturer survey \\
\hline Raw material extraction processing & Ecoinvent Database: PRé Consultants and Sylvatica, 2001 \\
\hline Energy/fuel utilized in processing & Ecoinvent Database: PRé Consultants and Sylvatica, 2001 \\
\hline Emissions & Ecoinvent Database: PRé Consultants and Sylvatica, 2001 \\
\hline \multicolumn{2}{|l|}{ Refrigerator Component Manufacturing } \\
\hline Fuel: assembly and processing & Manufacturer survey \\
\hline Emissions & Ecoinvent Database: PRé Consultants and Sylvatica, 2001 \\
\hline \multicolumn{2}{|l|}{ Transportation } \\
\hline Fuel & Manufacturer survey \\
\hline Emissions & USLCI database: PRé Consultants and Sylvatica, 2001 \\
\hline \multicolumn{2}{|l|}{ Installation } \\
\hline Tooling emissions & USLCI database: PRé Consultants and Sylvatica, 2001 \\
\hline \multicolumn{2}{|l|}{ Operation } \\
\hline Life span energy use & Manufacturer survey \\
\hline $\begin{array}{l}\text { Energy and material use: reasonable } \\
\text { expectation of repairs }\end{array}$ & Manufacturer survey \\
\hline Emissions from tooling & USLCI database: PRé Consultants and Sylvatica, 2001 \\
\hline \multicolumn{2}{|l|}{ Disassembly and Recycling } \\
\hline Input materials and general process & Manufacturer survey \\
\hline Energy use for disassembly & USLCI database: PRé Consultants and Sylvatica, 2001 \\
\hline Incineration emissions & USLCI database: PRé Consultants and Sylvatica, 2001 \\
\hline Landfill consequences & USLCI database: PRé Consultants and Sylvatica, 2001 \\
\hline Reuse processing & USLCI database: PRé Consultants and Sylvatica, 2001 \\
\hline
\end{tabular}

To ensure quality of data, the three manufacturers surveyed in the research were also chosen from three different countries and regions used similar, but not identical machinery for extraction, manufacturing and assembling purposes. While many of these processes were unique, several processes for specific unit processes 
overlapped. Thus, in order to normalize the data for material, energy and emissions for each unit process, the overlapping data were averaged, and the mean of the data used as the primary input for the life cycle assessment. The collected data were used to construct the basic life cycle inventory for the traditional model. "Unit A" employs traditional injected polyurethane as the insulation and "Unit B" utilizes a non-traditional insulation applied to the cover and walls.

Eco-indicator $99(\mathrm{H})$ was chosen as the primary environmental impact assessment method. It was selected because of its relevance to chief environmental sustainability concerns associated with the production of different components of the commercial refrigerator. Indicators such as global warming potential, depletion of natural resources, and overall energy use were all determined to be critical metrics in determining whether a more sustainable design than Unit A is achieved.

\section{Results and Discussion}

\subsection{Energy Consumption and Heat Flux Testing}

Following an initial temperature anomaly at the commencement of testing (during hour 2) the ambient temperature remained at $75^{\circ} \mathrm{F}$ with an average deviation of $0.1^{\circ} \mathrm{F}$. There was a significant decrease in the internal temperatures of the units due to a 7 hour stabilization period where the internal cabinet air went from ambient room temperature to a standard operating temperature of $-11^{\circ} \mathrm{F}$. Accordingly, heat flux and power consumption monitoring commenced at hour 7 .

Figure 5 shows the results of the heat flux measured at sensor 1, the sensor closest to the west wall of the unit (refer to Figure 1). The heat flux for the polyurethane through this sensor fluctuated from $5.3 \mathrm{~W} / \mathrm{m}^{2}$ at hour 18 to $6.4 \mathrm{~W} / \mathrm{m}^{2}$ at hour 15 to. By comparison, the heat flux through this sensor for Unit B varied from a minimum heat flux of $3.5 \mathrm{~W} / \mathrm{m}^{2}$ at hour 8 to a peak of $3.9 \mathrm{~W} / \mathrm{m}^{2}$ at hour 10 . This suggests that the insulation utilized in Unit $\mathrm{B}$ had a more consistent thermal resistance.

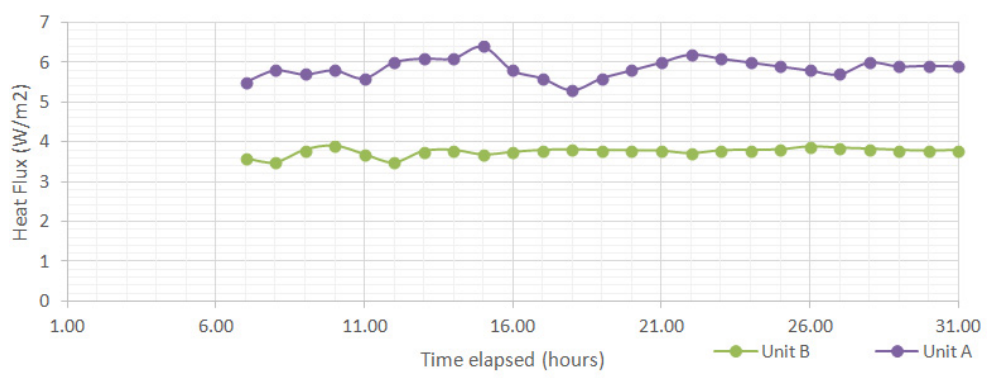

Figure 5. Time variation of heat flux through the cover of testing units A and B recorded at ensor 1

The time variation of the heat flux measured by sensor 2 is shown in Figure 6. Both sensors display similar trends in heat flux fluctuation with that of Unit A being more significant. Figure 6 shows that the lowest level of heat flux observed by sensor 2 in unit A was $5.5 \mathrm{~W} / \mathrm{m}^{2}$ occurring at hour 8 . The minimum heat flux for sensor 2 was $3.4 \mathrm{~W} / \mathrm{m}^{2}$ at hour 10 and the maximum was $6.7 \mathrm{~W} / \mathrm{m}^{2}$ at hour 19 . For Unit $\mathrm{B}$, There was a significant increase in heat flux through the insulation of Unit A between hour 18 and 19 , where an increase of $1.1 \mathrm{~W} / \mathrm{m}^{2}$ was observed.

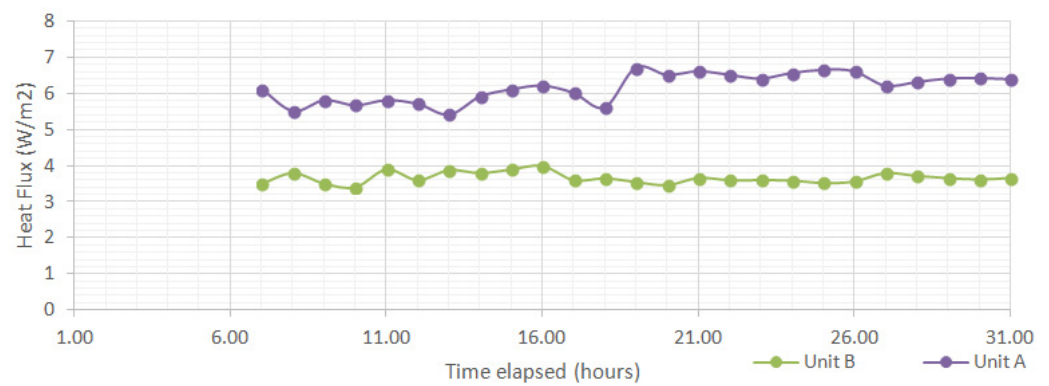

Figure 6. Heat flux through the cover of testing unit A and B recorded at sensor 2

When comparing Unit A to Unit B, it was observed that there was an average decrease in heat flux of approximately $40 \%$ across sensor 1 and sensor 2 , where the insulation varied from polyurethane in Unit A, to the 
modified insulation in Unit B. Additionally, there is less fluctuation in recorded values of heat flux in Unit B that is characteristic of a more uniform heat resistance configuration. This suggests that the honeycomb structure in conjunction with the primary insulator of vacuumed silica packets is an effective pairing for the purposes of thermal efficiency.

Because the ambient conditions and the internal temperature of the refrigerator/freezer remained more or less constant during the testing, the fluctuations in heat flux across each type of tested insulation are indicative of the effectiveness of the insulation materials and configuration. Since the insulation material had not changed across sensors 3 and 4, this is further supported by the heat flux data collected by the sensors located on the unit walls (Figures 7 and 8). The conventional insulation was not replaced in the walls of Unit B; this type of polyurethane insulation was utilized as the primary insulator for both Unit A and Unit B (except for the cover of Unit B). As shown, the heat flux remains relatively constant through Unit A and Unit B, and indicates that the heat flux was heavily dependent on the insulation material utilized in testing.

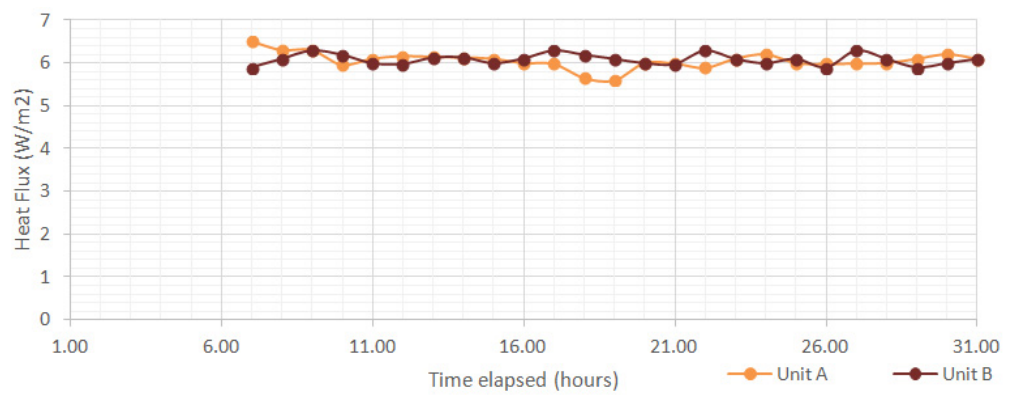

Figure 7. Heat flux through the cover of testing unit A and B recorded at sensor 3. The heat flux through the east wall (sensor 3) of the refrigerator/freezer unit remained relatively constant for Unit A and Unit B. Both units employed polyurethane insulation as the primary insulator.

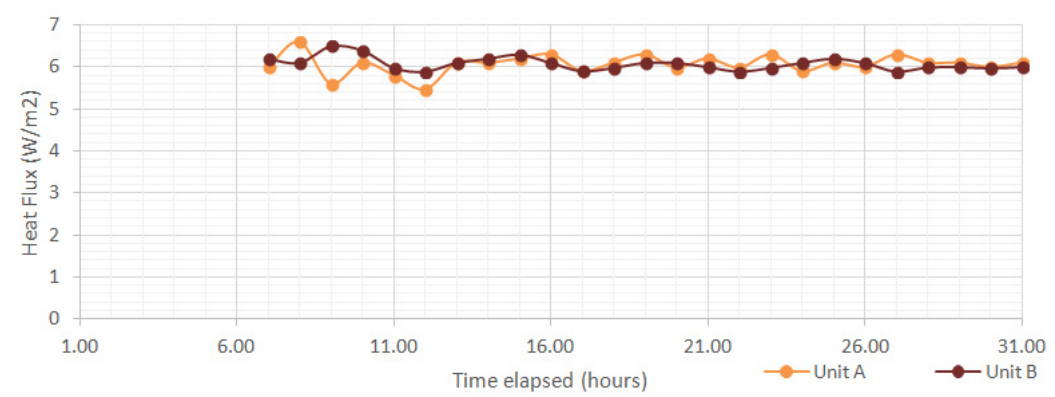

Figure 8. Time variation of heat flux through the cover of testing unit A and B recorded at sensor 4

Results of the power consumption measurements for both units are provided in Figure 9. The power meter 7 hours after the internal temperature had stabilized. Figure 9 shows the power consumption was consistently higher for Unit A. In fact, cumulative power consumption after 24 hours of testing was recorded to be $0.92 \mathrm{kWh}$ for Unit A and $0.869 \mathrm{kWh}$ for Unit B. The results indicate there is a marked increase in thermal and energy efficiency achieved by the use of the modified insulation in Unit B (when placed only in the unit's cover). On average, the alternative insulation performed $25-40 \%$ better with direct heat transfer. Consistent with this trend, there was an observed approximate 5\% reduction in overall energy usage per day. This is significant when considering the annual power consumption of a commercial refrigerator/freezer and the power consumption over the life time of the unit.

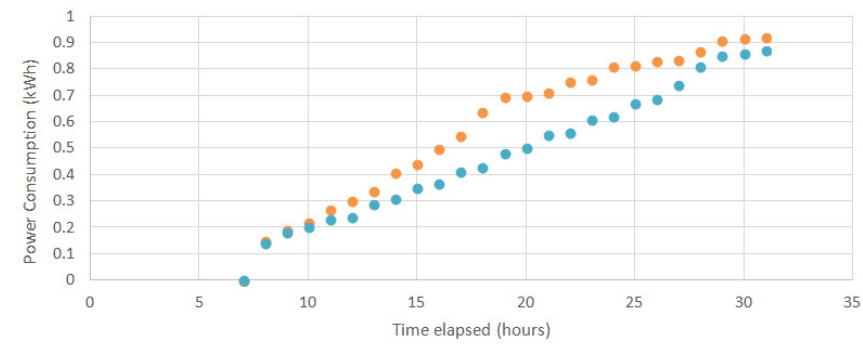

Figure 9. Cumulative power usage $(\mathrm{kWh})$ by Unit A and Unit B over 24 hours. Power usage was recorded on an hourly basis as each separate test was conducted 


\subsection{Life Cycle Assessment}

Figure 10 shows the characterization of Unit A and Unit B with respect to each key environmental sustainability impact category by the Eco-Indicator $99(\mathrm{H})$ assessment methodology. Eco-Indicator $99(\mathrm{H})$ utilizes a damage-oriented approach to quantify the impact of each system on emissions, land use, and resource depletion. In each of these three categories, there are indicators representative of the key metrics. For example, in the area of emissions some the impact indicators are: carcinogens (i.e., effects due to emissions of carcinogenic substances to air, water, and soil, expressed in Disability adjusted Life Years (DALY)/kg emission); and ozone layer depletion (ozone layer damage, expressed in DALY $/ \mathrm{kg}$ emission, due to increased UV radiation as a result of emission of ozone depleting substances to air). Eco-Indicator 99 utilizes a point system to determine the overall damage impact. The higher the point value, the larger the damage associated with that impact category. Figure 10 also shows the relatively lower impact of Unit B compared to Unit A in all impact categories.

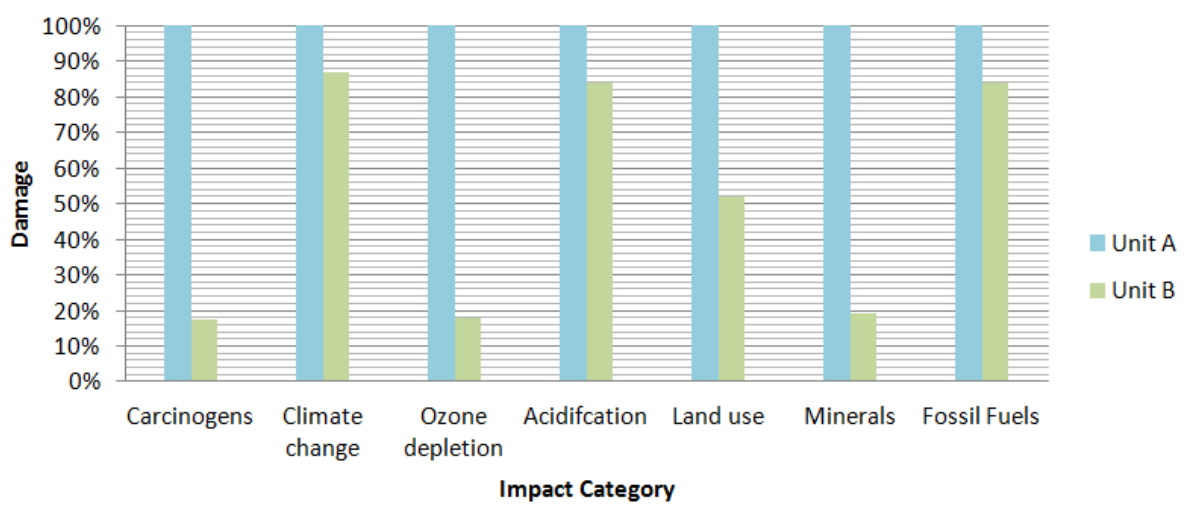

Figure 10. Characterization of Unit B relative to Unit A in each key environmental impact category

Figure 10 shows that the most significant relative decreases were noted in the areas of carcinogens, ozone depletion potential, and mineral usage, which experienced a relative decrease of over $80 \%$ when the modified insulation design was utilized in the refrigerator/freezer unit. The overall use of fossil fuels, a key metric in determining overall energy efficiency, showed a relative decrease of $16 \%$, which can be attributed to both the reduction in energy utilized in the use phase, and the energy saved from the production of additional insulation.

Figure 11 shows the normalized data from the analysis. For LCA normalization, the data obtained from the impact assessment is divided by the equivalent regional data to provide a better indication of which impact categories contributed the most to overall environmental impact. As shown, the normalized data revealed the most impactful category to be the use of fossil fuels.

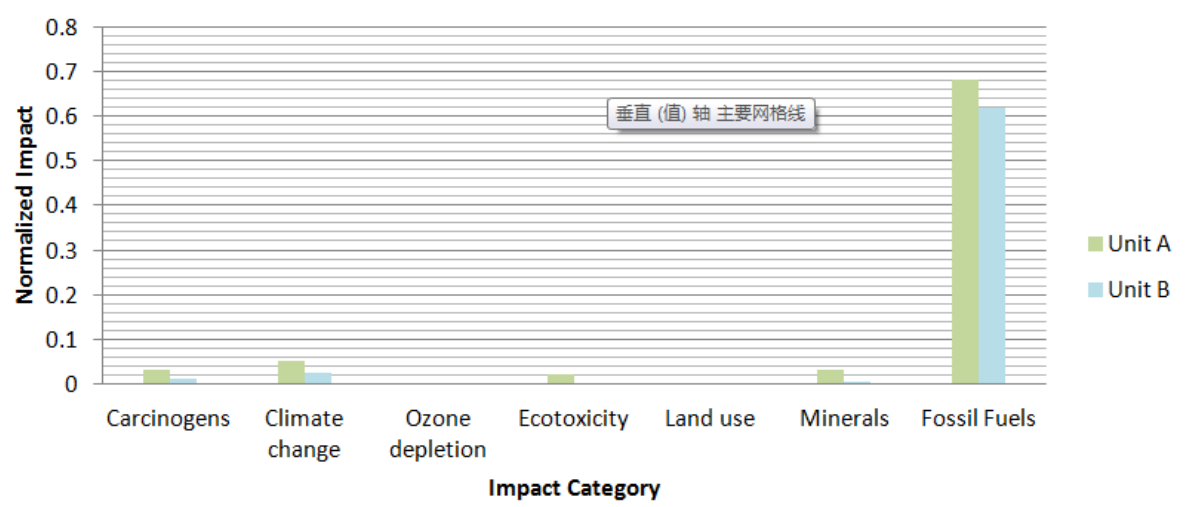

Figure 11. Normalization of each type of insulation in key environmental impact category based on equivalentEuropean data. Each impact indicator is shown in terms of its contribution to the overall life cycle impact

Other results obtained from the LCA (not provided) demonstrated that the value of the energy used during the total life cycle was estimated to be 5,862 MJ for Unit A and 4,698 MJ for Unit B, an overall decrease of about $20 \%$. The weighting scheme associated with Eco-Indicator 99 quantified the fossil fuel use for Unit A as 205 Pts., with Unit B carrying a lower overall impact of 192 Pts. 
The production of both units was energy intensive, utilizing 27\% (55 Pts.) of the total energy consumption for Unit A, and 38\% (73 Pts.) of the total energy consumption for Unit B. In particular, process contribution metrics from SimaPro indicated that the processes involved in the fabrication of the metal frame of the unit, as well as the forming of the plastic sheeting covering the unit expends a large amount of energy and greenhouse gas emissions. A similar trend also resulted from the fabrication of the mechanical components of both units, contributing 42 Pts. out of an estimated 55 for the manufacturing of Unit A, and 42 Pts. out of an estimated 73 for Unit B. Production of the insulation of Unit B was more energy intensive due to the energy associated with the production of silica, which contributed 24 Pts. However, a decrease in overall energy consumption was observed when an energy analysis was conducted over the life cycle of the unit, where the total points attributed to energy consumption for Unit A was 205 and Unit B carried a point value of 192, indicating that the impact points gained through the manufacturing phase was later offset by the lower point value in the use and disassembly phases.

A critical issue that was noted in the manufacturer survey was the management of waste and reuse of scrap metal from the manufacturing of mechanical components. Reusing metal discarded from previous production runs is important to conserving natural resources and ultimately mitigating the overall impact. Of the three manufacturers surveyed, only one reused scrap metal in the manufacturing. Assuming a U.S national energy mix, recycling one metric ton of steel would save approximately 1.1 metric tons of iron ore which results in savings of 2.79 metric tons of $\mathrm{CO}_{2} \mathrm{e}$ (EPA, 2013).

The use phase contributed more than $40 \%$ of the overall points toward the overall environmental impact. Thus, the operation phase presents a significant opportunity for energy efficiency improvement. In addition, over the complete life cycle of both units, the overall energy use from a unit employing a fully fabricated modified insulation system is expected to be approximately $15 \%$ less than that of the traditional unit, as supported by the literature, as well as the experimental metrics.

Results of the disposal and disassembly phase analysis by the Eco-Indicator $99(\mathrm{H})$ assessment method showed that Unit A utilized $36 \%$ greater landfill space (17.6 kg of Unit A was landfilled) due mainly to the voluminous amount of foam associated with the disposal. Alternatively, in Unit B, $86 \%$ of the insulation is recoverable for reuse, and hence only $11.3 \mathrm{~kg}$ of Unit B was landfilled. The overall energy use for disassembly was slightly greater for Unit B, attributed mainly to the additional energy needed to recover the modified insulation. However, this is offset by the significant amount of material salvaged, and the energy saved from not having to remanufacture the same insulation materials for a second production run.

Experimental and environmental assessment of the unit revealed that significant opportunities exist to reduce the overall environmental and energy impact of the commercial refrigerator unit are in the use phase, which can be achieved by reducing the energy consumption of these units on a daily basis. The commercial refrigerator/freezer unit investigated in this study that employed an alternate insulation provides an example of modifications that could be made to refrigerator design in order to increase the energy efficiency during the use phase. The experimental test conducted in this study showed that an estimated energy consumption improvement of 5.1\% over 24 hours was experienced by one unit employing the modified insulation in the cover of the unit alone, amounting to a significant energy savings of $373 \mathrm{kWh}$ over the lifetime of the refrigerator/freezer. This equates to a savings of roughly 0.257 metric tons of $\mathrm{CO}_{2} \mathrm{e}$ emissions for a singular unit over its 20 year life span (EPA, 2014). For a unit fully outfitted with the alternative insulation described in this work, energy savings of 1,119 $\mathrm{kWh}$ and 0.771 metric tons of $\mathrm{CO}_{2} \mathrm{e}$ emissions are expected.

\section{References}

Air-Conditioning, Heating and Refrigeration Institute (AHRI). (2011). Polyurethane and olyisocyanurate foams. Washington D. C.

American National Standards Institute (ANSI/ASHRAE). (2005). Method of testing commercial refrigerators and freezers ANSI/ASHRAE Standard 72-2. Atlanta, GA.

Bansal, P. K, Vineyard, E. A, \& Abdelaziz, O. A. (2011). Review and status of not-in-kind refrigeration technologies for household space conditioning, water heating and food refrigeration. International Journal of Sustainable Build Environment, 1(1), 85-101. http://dx.doi.org/10.1016/j.jisbe.2012.07.003

Boardman, B. (2004). Achieving energy efficiency through product policy: the UK experience. Environmental Science and Policy, 7(3), 165-176. http://dx.doi.org/10.1016/j.envsci.2004.03.002

Bouquerel, M., Duforestel, T., Baillis, D., Rusaouen, R. (2012). Heat transfer modeling in vacuum insulation panels containing nanoporous silicas-A review. Energy and Buildings, 54(2), 320-336. 
http://dx.doi.org/10.1016/j.enbuild.2012.07.034

Department of Energy (DoE). (2010). U.S residential and commercial buildings total primary energy consumption. Buildings Energy Data Book. Washington D.C.

Department of Energy (DoE). (2011). Commercial energy end-use splits. Buildings Energy Data Book. Washington D.C.

Eberhardt, H. F. (2007). Vacuum Insulation Panels (VIP) in energy efficient cooling appliances for improving the environment of our children's world. Proceedings of the $8^{\text {th }}$ International Vacuum Insulation Symposium, March 2007.

Energy Star (EPA). (2011). Buy products that make a difference. Washington D.C. Retrieved from http://www.energystar.gov/certified-products/detail/commercial_refrigerators_freezer

Environmental Protection Agency (EPA). (2009). Substitutes in rigid polyurethane. Washington D.C. Retrieved from http://www.epa.gov/ozone/snap/foams/lists/appliance.html

Environmental Protection Agency (EPA). (2011). Global Warming Potentials of ODS Substitutes, Ozone layer protection. Washington D.C.. Retrieved from http://www.epa.gov/ozone/geninfo/gwps.html

Environmental Protection Agency (EPA). (2013). Waste Reduction Model (WARM). Washington D.C. Retrieved from http://www.epa.gov/climatechange/wycd/waste/calculators/Warm_Form.html

Environmental Protection Agency (EPA). (2014), Greenhouse Gas Equivalencies Calculator. Washington D.C. Retrieved from http://www.epa.gov/cleanenergy/energy-resources/calculator.html

Fricke, J., Hummer, E., \& Scheuerpflug, P. (1995). A Study of Thermal Properties of Silica Aerogels. Proceedings of 2nd International Symposium of Aerogel, April 2005.

Kudoh, A., Ohira, H., Nakamura, K., \& Araki, K. (2006). Simple method to support optimization of layouts for vacuum insulation panels (VIPs) for refrigerator. Heat Transfer Asian Research, 35(6), 58-63.

Kwon, J. S., Jang, C. H., Jung, H., \& Song, T. H. (2009). Effective thermal conductivity of various filling materials for vacuum insulation panels. International Journal of Heat and Mass Transfer, 52(23-24), 55255532. http://dx.doi.org/10.1016/j.ijheatmasstransfer.2009.06.029

Mahlia, T. M., \& Saidur, I. (2010). A review on test procedure, energy efficiency standards and energy labels for room air conditioners and refrigerator-freezers. Renewable and Sustainable Energy Reviews, 14(7), 18881900. http://dx.doi.org/10.1016/j.rser.2010.03.037

Parenti, V. (2007, June). Novel rigid polyurethane formulations offering combined high energy efficiency and fast productivity for outstanding performance in the domestic appliance industry. Paper presented at Polyurethane Technical Conference, Orlando, FL.

U.S Energy Information Administration (USEIA). (2011). Annual Energy Review 2011. Washington D.C.

Waide, P., Lebot, B., \& Hinnells, M. (2002). Appliance energy standards in Europe. Energy and Buildings, 45(67), 56-80.

Weaver, P. M., Ashby, M. F., Burgess, S., \& Shibaike, N. M. (1996). Selection of materials to reduce environmental impact: A case study on refrigerator insulation. Materials \& Design, 17(1), 11-17. http://dx.doi.org/10.1016/0261-3069(96)00024-6

World Energy Council (WEC). (2013). Energy Efficiency Policies around the World: Review and Evaluation. London, U.K.

Yu, F., Li, Y., \& Zhu, Y. (2009). Numerical and experimental investigation of the thermal insulation performance of low temperature cold box. International Communication in Heat and Mass Transfer, 36(9), p.908-911. http://dx.doi.org/10.1016/j.icheatmasstransfer.2009.05.008

Zhao, Y. (2006). Research on synthesis process of silica aerogel/polystyrene core/shell composite materials.

\section{Copyrights}

Copyright for this article is retained by the author(s), with first publication rights granted to the journal.

This is an open-access article distributed under the terms and conditions of the Creative Commons Attribution license (http://creativecommons.org/licenses/by/3.0/). 